\title{
Membrane separation of enzyme-converted biomass compounds: Recovery of xylose and production of gluconic acid as a value-added product
}

Morthensen, Sofie Thage; Zeuner, Birgitte; Meyer, Anne S.; Jørgensen, Henning; Pinelo, Manuel

Published in:

Separation and Purification Technology

Link to article, DOI:

10.1016/j.seppur.2017.11.031

Publication date:

2018

Document Version

Peer reviewed version

Link back to DTU Orbit

Citation (APA):

Morthensen, S. T., Zeuner, B., Meyer, A. S., Jørgensen, H., \& Pinelo, M. (2018). Membrane separation of enzyme-converted biomass compounds: Recovery of xylose and production of gluconic acid as a value-added product. Separation and Purification Technology, 194, 73-80. https://doi.org/10.1016/j.seppur.2017.11.031

\section{General rights}

Copyright and moral rights for the publications made accessible in the public portal are retained by the authors and/or other copyright owners and it is a condition of accessing publications that users recognise and abide by the legal requirements associated with these rights.

- Users may download and print one copy of any publication from the public portal for the purpose of private study or research.

- You may not further distribute the material or use it for any profit-making activity or commercial gain

- You may freely distribute the URL identifying the publication in the public portal 


\section{Accepted Manuscript}

Membrane separation of enzyme-converted biomass compounds: Recovery of xylose and production of gluconic acid as a value-added product

Sofie T. Morthensen, Birgitte Zeuner, Anne S. Meyer, Henning Jørgensen, Manuel Pinelo

PII: S1383-5866(17)32591-1

DOI: https://doi.org/10.1016/j.seppur.2017.11.031

Reference: SEPPUR 14187

To appear in: Separation and Purification Technology

Received Date:

9 August 2017

Revised Date:

9 November 2017

Accepted Date:

11 November 2017

Please cite this article as: S.T. Morthensen, B. Zeuner, A.S. Meyer, H. Jørgensen, M. Pinelo, Membrane separation of enzyme-converted biomass compounds: Recovery of xylose and production of gluconic acid as a value-added product, Separation and Purification Technology (2017), doi: https://doi.org/10.1016/j.seppur.2017.11.031

This is a PDF file of an unedited manuscript that has been accepted for publication. As a service to our customers we are providing this early version of the manuscript. The manuscript will undergo copyediting, typesetting, and review of the resulting proof before it is published in its final form. Please note that during the production process errors may be discovered which could affect the content, and all legal disclaimers that apply to the journal pertain. 
Membrane separation of enzyme-converted biomass compounds: Recovery of xylose and production of gluconic acid as a value-added product

Sofie T. Morthensen ${ }^{1}$, Birgitte Zeuner ${ }^{1}$, Anne S. Meyer ${ }^{1}$, Henning J $\phi r g e n s e n^{1,2}$, Manuel Pinelo $^{1 *}$

${ }^{1}$ Department of Chemical and Biochemical Engineering, Technical University of Denmark, Søltofts Plads Building 229, 2800 Kongens Lyngby, Denmark.

${ }^{2}$ Present Address: Department of Plant and Environmental Sciences, University of Copenhagen, Thorvaldsensvej 40, 1871 Frederiksberg C, Denmark.

${ }^{*}$ Corresponding author: $\underline{\mathrm{mp} @ \mathrm{kt} . \mathrm{dtu} . \mathrm{dk}}$ (M. Pinelo)

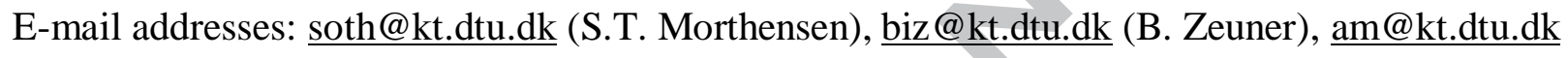
(A.S. Meyer), hej@plen.ku.dk (H. Jørgensen) 


\section{Abstract}

The purpose of the present study was to assess the efficiency of enzyme-assisted nanofiltration for separation of xylose from glucose present in genuine biorefinery liquors obtained from hydrothermal pretreatment of wheat straw, corn stover and Miscanthus stalks. Glucose oxidase and catalase were used to convert the glucose contained in the liquors into gluconic acid, so xylose could be more easily recovered in the subsequent nanofiltration. Subjecting the biomass liquors to dilute acid treatment and centrifugation before the enzymatic reaction and filtration led to maximum biocatalytic performance of the membrane bioreactor (neglectable fouling and no enzyme activity loss) during five consecutive reaction-filtration cycles. The best separation factor of gluconic acid over xylose in the subsequent nanofiltration was $2.7,2.5$ and 2.2 for wheat straw, corn stover and Miscanthus stalks, respectively. All represented a significant improvement compared to the benchmark separation of xylose and glucose, in which case the separation factor was only 1.4. However, the higher ionic strength of the biomass liquors compared to the pure model solution probably led to a less negative zeta potential of the nanofiltration membrane, which significantly reduced the xylose purification performance as compared to the model system, for which the separation factor was 34 .

\section{Keywords:}

Membrane bioreactor, biomass liquor, glucose oxidase/catalase, sugars, low-pressure nanofiltration 


\section{Introduction}

Lignocellulose is an abundant and renewable raw material, which is expected to replace fossil resources as feedstock for production of several types of chemical products on the pathway towards a future bio-based society [1]. However, in order for lignocellulose to become a suitable feedstock for biorefineries, it is necessary to develop efficient separation and conversion technologies that will ensure feasible utilization of the biomass [2]. For instance, enhancing the separation of monosaccharides (e.g. xylose and glucose) obtained after lignocellulose pretreatment could enable the production of specific building block chemicals for various industrial applications. Recently, we demonstrated that the separation of xylose and glucose could be significantly improved via enzymeassisted nanofiltration (NF), in which glucose is first enzymatically converted to gluconic acid leading to efficient xylose purification due to electrostatic repulsion between gluconic acid (i.e. gluconate) and the surface of the NF270 membrane [3]. Gluconic acid, which is an important compound used in e.g. the food industry [4], can be obtained from glucose via enzymatic oxidation of glucose to gluconic acid, either by cofactor-dependent glucose dehydrogenase catalysis or via oxygen-dependent glucose oxidase catalysis [5]. Based on our studies conducted on pure model solutions of xylose and glucose, also involving enzyme immobilization in membrane bioreactors [6], it was concluded that the highest yields, purities and throughputs of xylose and gluconic acid could be obtained using free glucose oxidase in the membrane bioreactor [7]. However, when enzyme-assisted membrane separation is performed on genuine biorefinery liquors, additional challenges related to e.g. enzyme inhibition [8] and fouling formation [9] may reduce the performance of the membrane bioreactor. Moreover, the presence of various carbohydrates, proteins, phenolics, acids, salts and furans in the biomass liquors could further complicate the downstream separation by NF as opposed to the simpler model solutions, for which efficient purification of monosaccharides has been rather easily accomplished [10-13]. First of all, identifying proper membranes and process conditions that favor the slight differences in solute 
properties (e.g. size and charge) leading to separation may be difficult. Secondly, in a polyelectrolyte system such as the biomass liquors employed in this study, a combination of charge interactions are likely, leading to e.g. a Donnan effect, which may further be influenced by the $\mathrm{pH}$ and solute concentration [14]. Moreover, the membrane surface charge (i.e. zeta potential) can also be affected by the ionic strength of the solution [15], which in turn may impact the electrostatic repulsion and influence the overall separation performance. Thus, the present work was undertaken to assess the applicability of the glucose oxidase assisted membrane separation (in practice a glucose oxidase/catalase system) on genuine biomass liquors obtained directly after hydrothermal pretreatment of wheat straw (WS), corn stover (CS) and Miscanthus stalks (MS), and to further investigate the possible impact of solute interactions on the downstream purification as a function of $\mathrm{pH}$ and solute concentration.

\section{Materials and Methods}

\subsection{Equipment, chemicals and membranes}

Enzymatic reactions and filtrations were conducted in a magnetically stirred dead-end cell (Amicon 8050, Millipore, USA). Dead-end filtration was selected as filtration mode, as it provides the most comprehensive insight of the effects of fouling during filtration. The biomass liquors were obtained after hydrothermal pretreatment $\left(190^{\circ} \mathrm{C}, 10 \mathrm{~min}\right)$ and pressing (leading to solid-liquid fractionation) of WS, CS and MS as described in [16]. Compositions of the biomass liquors are shown in Table 1. Hydrogen peroxide solution (30 wt. \% in $\mathrm{H}_{2} \mathrm{O}$ ), glucose oxidase (“GOD”, EC 1.1.3.4, $160 \mathrm{kDa}, 128$ U/mg solid) from Aspergillus niger and catalase (“CAT”, EC 1.11.1.6, $250 \mathrm{kDa}, 7741 \mathrm{U} / \mathrm{mg}$ protein) from Aspergillus niger were purchased from Sigma-Aldrich (Steinheim, Germany). Analytical standards, D(+)-Glucose ( $\geq 99.5 \%)$, D-xylose ( $\geq 99 \%)$, L-(+)-arabinose ( $\geq 99 \%)$, sodium formate $(>99 \%)$, sodium acetate trihydrate ( $>99 \%)$, D-gluconic acid sodium salt ( $\geq 99 \%)$, furfural (99\%), hydroxymethyl furfural (HMF) ( $\geq 99 \%$ ), vanillic acid, vanillin (99\%), ferulic acid (99\%), 4- 
hydroxybenzoic acid (99\%), 4-hydroxybenzaldehyde (98\%), p-coumaric acid ( $\geq 98 \%)$, syringic acid ( $\geq 98 \%$ ), syringaldehyde (99\%), and sinapic acid ( $\geq 99 \%)$ were also purchased from Sigma-Aldrich.

Dow-Filmtec NF270 membranes were purchased from Sterlitech (Kent, USA), while ultrafiltration

(UF) PLGC membranes were purchased from Merck Millipore (Darmstadt, Germany). The main properties of the membranes are shown in Table 2.

\begin{tabular}{|c|c|c|c|c|c|}
\hline & $\begin{array}{l}\text { Wheat straw (WS) } \\
\text { Pretreatment }^{\text {liquor }}(\mathrm{g} / \mathrm{L}) \\
\end{array}$ & $\begin{array}{l}\text { Wheat straw (WS) } \\
\text { Dilute acid post } \\
\text { hydrolysis liquor }\end{array}$ & $\begin{array}{l}\text { Corn stover (CS) } \\
\text { Dilute acid post } \\
\text { hydrolysis liquor }\end{array}$ & $\begin{array}{c}\text { Miscanthus stalks (MS) } \\
\text { Dilute acid post } \\
\text { hydrolysis liquor }\end{array}$ & $\begin{array}{c}\text { Model } \\
\text { solution }\end{array}$ \\
\hline Glucose & 0.5 & $9.4(15)$ & $14.1(15)$ & $18.4(15)$ & 15 \\
\hline Xylose & 1.7 & $46.8(135)$ & $48.8(135)$ & $30.8(135)$ & 135 \\
\hline Arabinose & 1.9 & 6.8 & 8.2 & $3.8(3.1)$ & - \\
\hline Formic acid & 4.8 & 5.6 & 6.2 & $4.6(3.8)$ & - \\
\hline Acetic acid & 17.0 & 24.8 & 27.2 & $19.9(16.2)$ & - \\
\hline Furfural & 0.9 & 5.3 & 2.3 & $2.4(2.0)$ & - \\
\hline HMF & 0.1 & 0.6 & 0.2 & $2.0(1.6)$ & - \\
\hline Phenols & 0.3 & 0.3 & 0.7 & $0.4(0.3)$ & - \\
\hline Total salt & 16.8 & $-\infty$ & - & - & - \\
\hline
\end{tabular}

Table 1. Composition of biomass liquors (before and after dilute acid hydrolysis) and the model solution $(\mathrm{mM})$. Total phenolic content is given as the sum of vanillic acid, vanillin, ferulic acid, $p$ coumaric acid and 4-hydroxybenzaldehyde detected in the biomass liquors (4-hydroxybenzoic acid, syringic acid, syringaldehyde, and sinapic acid were not detected). Total salt content is the sum of aluminium, calcium, copper, iron, potassium, magnesium, manganese, sodium, nickel, phosphor, sulfur and zinc detected in the wheat straw pretreatment liquor. The values in brackets are the solute concentrations in the spiked solutions (MS liquor was diluted $\sim 1.2$ times before adding xylose). ${ }^{1}$ The concentration of oligosaccharides in the WS pretreatment liquor was estimated to $9.6 \mathrm{gL}^{-1}$ using eq. (9).

\begin{tabular}{|l|c|c|}
\hline & PLGC (UF) & NF270 (NF) \\
\hline Skin layer & Regenerated cellulose & Polyamide \\
\hline MWCO $(\mathrm{Da})$ & 10,000 & $150-200$ \\
\hline Water permeability $\left(\mathrm{Lm}^{-2} \mathrm{~h}^{-1} \mathrm{bar}^{-1}\right)^{\mathrm{a}}$ & $48.4-62.7$ & $16.6-17.7$ \\
\hline Isoelectric point $(\mathrm{IEP})$ & - & $\sim 5.0[12]$ \\
\hline Manufacturer & Merck Millipore & DOW-Filmtec \\
\hline
\end{tabular}

Table 2. Main properties of ultrafiltration (PLGC) and nanofiltration (NF270) membranes used in this work. 


\subsection{Water permeability tests}

Virgin NF270 membranes were soaked in $50 \%$ ethanol solution for $15 \mathrm{~min}$ - according to the manufacturers' guidelines - followed by filtration with deionized water at 4 bar for 20 min. Virgin UF membranes (PLGC) were soaked in ethanol (50\%) for 5 minutes and subsequently washed with sodium hydroxide ( $\mathrm{pH} \mathrm{10)}$ for 1 hour and water for $20 \mathrm{~min}$. The water permeability (WP) of the membranes was then measured at 4, 3, 2 and 1 bar at room temperature. After filtration of the biomass solutions, the WP test was repeated in order to determine the WP loss. After the WP test, PLGC membranes were immersed in $10 \%$ ethanol solution and stored at $5{ }^{\circ} \mathrm{C}$. If the virgin permeabilities were regained after storage in $10 \%$ ethanol solution at $5{ }^{\circ} \mathrm{C}$, the PLGC membranes were reused in more experiments.

\subsection{Post treatment of biomass liquors}

In order to optimize the flux and biocatalytic performance of the membrane bioreactor, the biomass pretreatment liquors were subjected to different post treatments. First, the biomass pretreatment liquor was subjected to centrifugation (Heraeus Multifuge 4 KR Centrifuge, Thermo Scientific, Waltham, MA, USA). Secondly, the biomass pretreatment liquor was subjected to acid hydrolysis in order to decompose the soluble poly- and oligosaccharides and in turn increase the yield of monosaccharides. Acid hydrolysis was accomplished by adding $9 \mathrm{~mL} \mathrm{H}_{2} \mathrm{SO}_{4}(97 \mathrm{w} / \mathrm{w} \%$ ) to $400 \mathrm{~mL}$ biomass pretreatment liquor, which was subsequently autoclaved at $121^{\circ} \mathrm{C}$ for $10 \mathrm{~min}$. After acid hydrolysis, $\mathrm{CaCO}_{3}(16-18 \mathrm{~g}$ pr. $400 \mathrm{~mL}$ liquor) was added to the liquor $(\mathrm{pH}<1)$ in order to precipitate $\mathrm{CaSO}_{4}$ and thereby increase the $\mathrm{pH}$ to 5.5. The liquors were subjected to centrifugation in order to remove the precipitated calcium salt. Some of the acid post-treated samples were additionally spiked with xylose and glucose in order to obtain the same monosaccharide concentration as in the model solution, i.e. $135 \mathrm{mM}$ xylose and $15 \mathrm{mM}$ glucose (Table 1), studied in [3] and [6]. A molar ratio xylose:glucose 9:1 was found to be the optimal for the subsequent separation of xylose from gluconic acid, for which a separation factor of 34 was reported [3]. 


\subsection{Biocatalytic reaction and filtration using pretreated and post-treated WS liquors}

$19.5 \mathrm{~mL}$ pretreated and post-treated WS liquor, respectively, was transferred to the dead-end cell equipped with the PLGC membrane and a stir bar. $300 \mathrm{U}$ GOD $(\sim 500 \mu \mathrm{l})$ and $900 \mathrm{U}$ CAT $(\sim 4 \mu \mathrm{l})$ were then added, and hydrogen peroxide solution $(\sim 68 \mu \mathrm{l})$ was added to a total concentration of 30 $\mathrm{mM}$. Biocatalytic reactions were conducted for $40 \mathrm{~min}$ at $35^{\circ} \mathrm{C}, \mathrm{pH} 5.5$ and $100 \mathrm{rpm}$ [3]. After the reaction, each solution was subjected to UF at 4 bar until $20 \mathrm{~mL}$ permeate was achieved and the reactor completely emptied (except for the enzymes which were still retained). The agitation speed during filtration was 100 and $250 \mathrm{rpm}$, respectively, for WS pretreatment liquors and $250 \mathrm{rpm}$ for post-treated WS liquors. Retentate and permeate samples were collected for quantitative analysis.

\subsection{Consecutive cycles in the membrane bioreactor using acid post-treated WS, CS and MS liquors}

After optimizing the flux and biocatalytic performance using the WS liquors, five consecutive reaction-separation cycles were performed with spiked acid hydrolyzed liquors from WS and CS, respectively. For the MS liquors, the glucose concentration was already higher $(>15 \mathrm{mM})$ than that in the model solution (Table 1). Therefore, in order to reach the glucose concentration of the model solution, the MS liquor was first diluted with water to a concentration of $15 \mathrm{mM}$ glucose (dilution factor 1.2 ) and subsequently spiked with xylose to a concentration of $135 \mathrm{mM}$. The concurrent dilution of the remaining components in the MS liquor was considered neglectable. In the first cycle, hydrolyzed biomass liquors (WS, CS and MS, respectively), enzymes and hydrogen peroxide $(30 \mathrm{mM})$ were added according to the procedure explained in section 2.4. Since enzymes were only added in the first cycle, $20 \mathrm{~mL}$ hydrolyzed biomass liquor and $68 \mu \mathrm{l}$ hydrogen peroxide solution were then added in each of the four subsequent cycles. After each 40-min reaction cycle, the dead-

end cell equipped with the PLGC membrane was emptied by applying a pressure of 4 bar. Agitation was set to $250 \mathrm{rpm}$, and the flux was recorded for each filtration cycle. Permeate samples were collected for quantitative analysis. 
In order to evaluate the performance of the downstream separation, the permeate samples (WS, CS and MS) obtained from the consecutive cycles in the membrane bioreactor were subjected to lowpressure NF with the NF270 membrane. Electrostatic repulsion and the Donnan effect were the mechanisms mostly discussed with respect to the separation of the charged solutes (i.e. gluconic acid, formic acid and acetic acid) in the NF step (cf. section 3.3). For clarification, electrostatic repulsion is here regarded as interactions between solutes and the membrane surface, which is governed by the membrane zeta potential, while Donnan effect is regarded as solute interactions caused by lack of ion equilibrium across the membrane, which in turn is governed by the difference in ion permeability. It is anticipated that the co-existence of and competition between electrostatic repulsion and the Donnan effect govern the overall separation of charged solutes by NF.

\subsubsection{NF of WS, CS and MS}

Formation of gluconic acid in the membrane bioreactor caused the solution $\mathrm{pH}$ to drop from 5.5 to 4.8. Prior to the NF step, $\mathrm{pH}$ of the permeate samples was readjusted to 7.4 and 9.5 , respectively, by adding sodium hydroxide. The liquors were then subjected to NF with the NF270 membrane at 4 bar and room temperature. For samples at $\mathrm{pH} 7.4$ and 9.5, the filtration was conducted until a volume reduction factor of 2 was achieved. For samples at $\mathrm{pH} 4.8$, the flux was so low that the filtration was only conducted until a volume reduction factor of 1.25. In all cases, agitation was set to $250 \mathrm{rpm}$, and the flux was recorded. Permeate and retentate samples were collected for quantitative analysis.

\subsubsection{NF of WS, CS and MS spiked with acetic acid}

In order to further investigate the separation mechanisms governing NF, the permeate samples (WS, $\mathrm{CS}$ and MS at $\mathrm{pH}$ 4.8) obtained from the consecutive cycles in the membrane bioreactor were spiked with acetic acid to a total concentration of $100 \mathrm{mM}$ acetic acid. In order to modify $\mathrm{pH}$ and study the effect of adding additional charged species on Donnan's effect, acetic acid was selected, 
as it was already present in the liquor. The addition of acetic acid caused the solution $\mathrm{pH}$ of the biomass liquors to drop to 4.1. The spiked liquors were subjected to NF according to the procedure described in section 2.5.1. Three additional experiments were performed with the permeate samples (WS, CS and MS at pH 4.8) from the membrane bioreactor. First, $\mathrm{pH}$ of the CS liquor was adjusted to $\mathrm{pH} 9.5$ with $10 \mathrm{M} \mathrm{NaOH}$ and then acetic acid was added to a total concentration of $100 \mathrm{mM}$ resulting in a solution $\mathrm{pH}$ of 4.6. The same procedure was applied to the WS and MS liquors; however the $\mathrm{pH}$ of these solutions was further readjusted to $\mathrm{pH} 9.7$ and $\mathrm{pH} 8.9$ for WS and MS, respectively. The spiked liquors were subjected to NF according to the procedure described in section 2.5.1.

\subsection{Analytical methods}

\subsubsection{Determination of monosaccharides, aliphatic acids and furans}

The concentration of monosaccharides (glucose, xylose and arabinose) and aliphatic acids (gluconic acid, formic acid and acetic acid) was quantified by HPLC (Shimadzu, Japan) according to the method described in [7] for the determination of lactic acid and pyruvate. Furans (furfural and HMF) were analyzed using a prominence diode array (PDA) detector. Only when glucose was present in the samples, the gluconic acid and glucose concentrations were quantified by HPAECPAD as described previously in [3].

\subsubsection{Determination of phenolic compounds}

Hydroxycinnamic acids (ferulic acid, $p$-coumaric acid, and sinapic acid), phenolic aldehydes (vanillin, 4-hydroxybenzaldehyde, and syringaldehyde), and phenolic acids (vanillic acid, 4hydroxybenzoic acid, and syringic acid) were quantified by reversed-phase high performance liquid chromatography (RP-HPLC) with DAD detection according to the method described in [17].

\subsubsection{Determination of crude protein}


The concentration of total nitrogen in the biomass liquors was determined using the Laton total nitrogen cuvette test (Hack Lange, Germany). Crude protein concentration was then calculated from the total nitrogen content by means of a default (Kjeldahl) conversion factor of 6.25 assuming 0.16 gram nitrogen per gram of protein $[18,19]$.

\subsubsection{Detection of oligosaccharides}

Oligosaccharides were detected by size exclusion chromatography according to the method described in [20].

\subsubsection{Determination of salts}

Inductively coupled plasma mass spectrometry (ICP-MS) was used for determining the concentration of chemical elements (aluminium, calcium, copper, iron, potassium, magnesium, manganese, sodium, nickel, phosphor, sulfur, zinc) in the WS pretreatment liquor. ICP-MS was performed by Novozymes A/S (Bagsværd, Denmark).

\subsection{Statistical analysis}

One-way ANOVA for determination of statistical significance was performed in RStudio (RStudio, Inc., Boston, MA, USA) using Tukey's test. Statistical significance was evaluated at the $p<0.05$ level.

\subsection{Calculated parameters}

The membrane water permeability $\left(L_{p}\right)$ was calculated using eq. (1):

$L_{p}=\frac{J_{w}}{T M P}$

where $J_{w}$ denotes the water flux and TMP the transmembrane pressure. The loss of membrane permeability was obtained from a comparison between the water permeability before filtration $\left(L_{p, i}\right)$ and after filtration and 20-min water wash $\left(L_{p, f}\right)$ : 
Permeability loss $=\left(1-\frac{L_{p, f}}{L_{p, i}}\right) \cdot 100 \%$

The observed solute retention $\left(R_{o b s}\right)$ was calculated according to eq. (3), in which $c_{p}$ is the permeate concentration and $c_{f}$ the feed concentration:

$R_{o b s}=1-\frac{c_{p}}{c_{f}}$

The biocatalytic productivity was calculated using eq. (4), in which $m$ is mass:

Biocatalytic productivity $=\frac{m(\text { products })}{m(\text { enzymes })}$

The normalized flux of cycle $i$ compared to cycle 1 was calculated using eq. (5):

Normalized flux $=\frac{\text { Flux }(\text { cycle } i)}{\text { Flux }(\text { cycle } 1)} \cdot 100 \%$

The separation factor of gluconic acid over xylose was calculated by means of eq. (6), in which $R_{o b s, X y l}$ and $R_{o b s, G A}$ are the observed retentions of xylose (Xyl) and gluconic acid (GA), respectively.

$X_{G A / x y l}=\frac{1-R_{o b s, X y l}}{1-R_{o b s, G A}}$

The xylose purity after NF was calculated by inserting the permeate concentration of xylose, gluconic acid, arabinose (Ara), formic acid (FA), acetic acid (Ac) and furfural (Fur) in eq. (7):

Xylose purity $=\frac{c_{p, X y l}}{c_{p, G A}+c_{p, X y l}+c_{p, A r a}+c_{p, F A}+c_{p, A c}+c_{p, F u r}} \cdot 100 \%$

When eq. (7) was used to calculate the xylose purity solely with respect to gluconic acid, $c_{p, a r a}, c_{p, F A}$, $\mathrm{c}_{\mathrm{p}, \mathrm{Ac}}$ and $\mathrm{c}_{\mathrm{p}, \text { Fur }}$ were removed from the denominator.

The yield of xylose in the permeate was calculated by inserting the feed and permeate concentrations, respectively, of xylose in eq. (8): 
Xylose yield $=\frac{c_{p, X y l}}{c_{f, X y l}} \cdot 100 \%$

Assuming that the monosaccharides and degradation products (i.e. furans and formic acid) present in the hydrolyzed WS liquor originate from the oligosaccharides present in the WS pretreatment liquor, the concentration of oligosaccharides $\left(\mathrm{gL}^{-1}\right)$ in the WS pretreatment liquor was estimated using eq. (9), in which FA is formic acid, and subscript letters before and after refer to the concentration of monosaccharides, furans and formic acid $\left(\mathrm{gL}^{-1}\right)$, respectively, before and after hydrolysis of the WS pretreatment liquor:

$[$ Oligosaccharides $]=[\text { Monosaccharides }]_{\text {after }}-[\text { Monosaccharides }]_{\text {before }}+[\text { furans }]_{\text {after }}-$ $[\text { furans }]_{\text {before }}+[F A]_{\text {after }}-[F A]_{\text {before }}$ 


\section{Results and discussion}

\subsection{Optimization of flux and biocatalytic productivity}

The performance of the membrane bioreactor was first evaluated using the crude WS pretreatment liquor. In the model system (pure solutions of xylose and glucose), the filtration time required to empty the UF reactor (20 mL, 2 bar, $100 \mathrm{rpm}$ ) was $10 \mathrm{~min}$, which with the WS pretreatment liquor increased to $140 \mathrm{~min}$ (Table 3). Furthermore, it was observed that the filtration of the WS pretreatment liquor produced a gel-like layer on the membrane surface. Since proteins and oligosaccharides are known to cause severe concentration polarization ultimately leading to gelation and fouling in UF operations [21,22], it was speculated whether such gel formation was due to the presence of proteins/peptides $(\sim 100 \mathrm{mg} / \mathrm{l}$ crude protein measured in the WS pretreatment liquor) and/or oligosaccharides ( 1 to $110 \mathrm{kDa}$ (primarily 1 to $12 \mathrm{kDa}$ ) detected in the WS pretreatment liquor). Besides the proteins naturally present in the feedstock, glucose oxidase and catalase could in principle also have contributed to some gel formation in the membrane bioreactor, although formation of a gel layer was never observed with the model solution. Due to the higher shear rate induced at the membrane surface [23], concentration polarization could be reduced by increasing the agitation to $250 \mathrm{rpm}$, which decreased the total filtration time (Table 3). Although the higher agitation rate could not prevent the formation of a gel layer, visually it could be seen that a more evenly distributed gel was obtained at $250 \mathrm{rpm}$, whereas the gel obtained at $100 \mathrm{rpm}$ was mainly located at the center of the membrane surface. The statistically insignificant difference between WP losses at $100 \mathrm{rpm}$ and $250 \mathrm{rpm}$ (Table 3) indicated that agitation did not have an effect on the irreversible fouling. In order to further enhance the permeate flux and thus decrease the total filtration time, the WS pretreatment liquor was exposed to different post treatments prior to the enzymatic reaction and filtration. First, subjecting the WS pretreatment liquor to centrifugation did not have a statistically signficant impact on the total filtration time. Although the WP loss remained the same with and without centrifugation, gel formation appeared most severe in the latter case, 
probably because the centrifugation step removed the insoluble material still present in the liquid phase after fractionation of the biomass, which could have contributed to some gel formation.

\begin{tabular}{|l|c|c|c|c|}
\hline \multicolumn{1}{|c|}{ Condition } & $\begin{array}{c}\text { Filtration time } \\
(\mathrm{min})\end{array}$ & $\begin{array}{c}\text { WP loss } \\
(\%)\end{array}$ & $\begin{array}{c}\text { Biocatalytic productivity } \\
\left(\text { mg gluconic acid/mg enzyme }^{\mathrm{a}}\right)\end{array}$ & $\begin{array}{c}\text { Glucose } \\
(\%)\end{array}$ \\
\hline $100 \mathrm{rpm}$ & $140 \pm 0^{\mathrm{A}}$ & $26.6 \pm 6.5^{\mathrm{A}}$ & $0.52 \pm 0.04^{\mathrm{C}}$ & $73^{\mathrm{B}} \pm 4.9$ \\
\hline $250 \mathrm{rpm}$ & $52.5 \pm 12.5^{\mathrm{B}}$ & $20.3 \pm 3.5^{\mathrm{AB}}$ & $0.60 \pm 0.01^{\mathrm{C}}$ & $84^{\mathrm{AB}} \pm 1.2$ \\
\hline $250 \mathrm{rpm}$ (cent.) & $36.5 \pm 3.5^{\mathrm{B}}$ & $20.9 \pm 2.0^{\mathrm{AB}}$ & $0.56 \pm 0.04^{\mathrm{C}}$ & $80^{\mathrm{B}} \pm 0$ \\
\hline $250 \mathrm{rpm}$ (hydr./cent) & $7.8 \pm 1.3^{\mathrm{C}}$ & $2.4 \pm 2.4^{\mathrm{B}}$ & $14.4 \pm 0^{\mathrm{B}}$ & $95^{\mathrm{A}} \pm 0$ \\
\hline $250 \mathrm{rpm}$ (hydr./spiked/cent.) ${ }^{\mathrm{b}}$ & $9 \pm 1^{\mathrm{C}}$ & $9 \pm 1^{\mathrm{AB}}$ & $22.8 \pm 0.22^{\mathrm{A}}$ & $95^{\mathrm{A}} \pm 0.9$ \\
\hline
\end{tabular}

${ }^{a}$ Total mass of glucose oxidase and catalase.

${ }^{\mathrm{b}}$ Increase in biocatalytic productivity was due to the spiked feed solution.

Table 3. Influence of various process parameters on the total filtration time, water permeability (WP) loss, biocatalytic productivity and glucose conversion (\%). Different superscript letters indicate statistically significant differences $(\mathrm{p}<0.05)$ of averages obtained. The one-way ANOVA analysis was done separately for each of the variables presented in the different columns. Abbreviations used: cent.: Before the filtration, the feed solution was subjected to centrifugation; hydr./cent.: Before the filtration, the feed solution was subjected to acid hydrolysis followed by centrifugation; hydr./spiked/cent.: Before the filtration, the feed solution was subjected to acid hydrolysis and spiked with glucose and xylose followed by centrifugation.

Subjecting the WS pretreatment liquor to dilute acid hydrolysis followed by centrifugation did have significant impact on the permeate flux, and consequently the total filtration time decreased to 10 min (Table 3). In this case, the permeability loss after filtration also decreased, and a gel layer was no longer observed. The absence of gel formation after the acid treatment was explained by the decomposition of longer oligosaccharides to shorter oligo- and monosaccharides, which was further verified by size exclusion HPLC, which showed that longer oligosaccharides (>1.3 kDa) were no longer detected in the WS solutions treated with acid. Since peptide bonds were not expected to be affected by the weak acid hydrolysis, it was concluded that mainly xylooligomers rather than proteins were responsible for the gel produced in the experiments without a post hydrolysis step. Moreover, extensive formation of foam - which is typically associated with proteins and peptides was observed in all the samples irrespective of post treatment, which could also sustain the hypothesis that the peptide bonds were still intact after acid hydrolysis. The disappearance of the gel 
layer after acid hydrolysis further suggested that glucose oxidase and catalase were not responsible for the gel formation, which was in good agreement with the observations previously made for the model solution. Finally, spiking the acid hydrolyzed WS liquor with glucose and xylose - in order to reach the same monosaccharide concentrations as in the model solution (i.e. $135 \mathrm{mM}$ xylose and $15 \mathrm{mM}$ glucose, respectively) - did not have an influence on the total filtration time nor the WP loss. Optimizing the process parameters with respect to the permeate flux further had a favorable impact on the biocatalytic productivity of the membrane bioreactor (Table 3 ). The dilute acid hydrolysis step significantly increased the biocatalytic productivity from 0.56 to $14.4 \mathrm{mg}$ gluconic acid/mg enzyme corresponding to an increase in glucose conversion from $73 \%$ to $95 \%$, respectively. The higher biocatalytic productivity obtained for the spiked solutions (23 mg gluconic acid/mg enzyme) was solely due the higher initial glucose concentration (i.e. $15 \mathrm{mM}$ ) in the feed, as the total glucose conversion was still 95\%. The lower membrane bioreactor performance obtained in the experiments without a dilute acid post hydrolysis step was ascribed to the gel layer formed on the membrane surface, which may have caused i) mass transfer limitations restricting the contact between substrates and enzymes and/or ii) adsorption/deposition of the enzymes and therefore loss of enzyme activity [24].

\subsection{Comparing membrane bioreactor performance for different biomass liquors}

In order to compare the membrane bioreactor performance for the biomass liquor and the model solution, five consecutive reaction-filtration cycles were conducted using the optimal process conditions from the preliminary experiments (i.e. $250 \mathrm{rpm}$ (hydr./spiked/cent)). Furthermore, hydrothermally pretreated, post-hydrolyzed CS and MS were also included in the study. Since the three biomass liquors were spiked with xylose and glucose to obtain the same initial feed concentration (Table 1), the membrane bioreactor maintained a biocatalytic productivity of $23 \mathrm{mg}$ gluconic acid/mg enzyme (data not shown) throughout five consecutive cycles irrespective of biomass feedstock. The biocatalytic performance of the real system was thus comparable with the 
performance of the model system, in which a biocatalytic productivity of $24 \mathrm{mg}$ gluconic acid/mg enzyme was obtained in each consecutive cycle [6]. It could therefore be concluded that even for extended reaction times, the presence of certain other components in the biomass liquors, such as acids and furans, did not inhibit glucose oxidase and catalase. Additionally, the WP loss was only 1$2 \%$ irrespective of the biomass feedstock. These results suggest that the biocatalytic productivity of the membrane bioreactor may be further enhanced by simply increasing the number of cycles. Moreover, the normalized flux for each consecutive cycle was compared for each of the three biomass liquors (Table 4). It was speculated whether the change in flux with each consecutive cycle could be correlated to the concentration of protein. However, the most significant decrease in permeate flux was obtained for the WS and CS liquors, whereas the highest crude protein concentration was measured in the MS liquor (approximately $140 \mathrm{mg} / \mathrm{l}$ crude protein versus 100 and $60 \mathrm{mg} / \mathrm{l}$ for WS and CS, respectively). Although a direct correlation between protein concentration and flux could not be obtained, there were clearly visual differences between the three biomasses. While the MS solution appeared rather clear, the WS and CS solutions were rather turbid. It was speculated whether such turbidity could be a consequence of significant phenol-protein interactions as previously reported for certain beverages $[25,26]$. However, since the phenolic content was generally very low in all the biomass liquors (Table 1), it seemed unlikely that phenol-protein interactions were the predominant cause of turbidity. Although a direct correlation between protein concentration, phenol concentration and permeate flux could not be found, turbidity was still concluded to be an important factor with respect to the change in permeate flux with each consecutive cycle. 


\begin{tabular}{|c|c|c|c|}
\hline Cycle & WS & CS & MS \\
\hline 1 & 100 & 100 & 100 \\
\hline 2 & $63 \pm 1$ & $55 \pm 3$ & $73 \pm 8$ \\
\hline 3 & $65 \pm 0$ & $53 \pm 2$ & $80 \pm 2$ \\
\hline 4 & $60 \pm 0$ & $48 \pm 1$ & $84 \pm 12$ \\
\hline 5 & $50 \pm 6$ & $51 \pm 0$ & $92 \pm 2$ \\
\hline
\end{tabular}

Table 4. Normalized flux (\%) calculated as percentage of the flux of the first cycle. WS = wheat straw; CS = corn stover; MS = Miscanthus stalks.

\subsection{Downstream separation}

In order to evaluate the performance of the downstream separation, the permeate streams leaving the membrane bioreactor were further subjected to low-pressure NF. Single-component model solutions based on a similar (WS) pretreatment liquor were previously evaluated in [27]. In the following discussion, the various interactions between solutes and between solutes and the membrane (Donnan effect and electrostatic repulsion in particular) in the multi-component solutions are assessed. Due to neglectable concentration of phenols in the biomass liquors (cf. Table 1), only sugars, furans and acids were considered in the evaluation of the separation performance.

\subsubsection{Non-charged solutes}

In the model solution [3], xylose $\left(150 \mathrm{Da}, \mathrm{pK}_{\mathrm{a}}=12.2\right.$ [28] $)$ was the only pentose sugar present in the feed for the NF. The xylose transport across the membrane was governed by size exclusion determined by the membrane cut-off (100-200 Da). In the biomass liquors, the pentose sugars were represented by xylose and arabinose $\left(150 \mathrm{Da}, \mathrm{pK}_{\mathrm{a}}=12.3\right.$ [28]), respectively. Due to the similar size and charge properties of the pentoses, the retentions of xylose and arabinose were generally comparable within each feedstock and $\mathrm{pH}$ value (Figure 1). Furthermore, the retention of pentoses in the real solutions was in most cases comparable with the retention of xylose in the model solution (41-45\% dependent on the $\mathrm{pH}$ ). As could be expected from the $\mathrm{pK}_{\mathrm{a}}$ values of the sugars, no obvious $\mathrm{pH}$ dependence was observed with respect to the solute retention. The transport of HMF (126 Da, $\mathrm{pK}_{\mathrm{a}}=12.8$ [29]) and furfural (96 Da) was most likely also governed by size exclusion, since both 
compounds should be non-charged at the investigated process conditions. The difference between WS and the other biomasses with respect to the furfural retention could be due to the higher concentration of furfural in the WS feed (more than twice as high in WS compared to CS and MS (Table 1)), which may have increased the diffusion as a result of the more significant furfural concentration gradient across the membrane. In the case of CS and MS, it was speculated whether the increase in furfural retention with increasing $\mathrm{pH}$ was a consequence of pore blocking as a result of more prominent pore swelling at high $\mathrm{pH}[14]$. However, since the WP loss was generally the same $(\sim 14 \%)$ at all $\mathrm{pH}$ values irrespective of the biomass type, the suggestion that pore blocking increased the furfural retention was rejected.

\subsubsection{Charged solutes}

In the model solution, gluconic acid $\left(196 \mathrm{Da}, \mathrm{pK}_{\mathrm{a}}=3.7\right.$ [4]) was the only charged solute present in the feed for the NF. Electrostatic repulsion was concluded to be the predominant separation mechanism leading to $98 \%$ retention of gluconic acid at $\mathrm{pH} 9.5$ [3]. Due to the high complexity of the pretreatment liquor, the influence of $\mathrm{pH}$ on the observed retention was investigated in order to evaluate the effect of the interaction between the different solutes (Figure 1). The results showed that the observed retention of gluconic acid was generally lower in the genuine liquors (irrespective of biomass type) as compared to the model solution, and also independent of $\mathrm{pH}$ even though the isoelectric point of the membrane $(\sim 5[12])$ was within the investigated range of $\mathrm{pH}$. These results suggest that not only electrostatic repulsion but rather a combination of several separation mechanisms were governing the transport of charged solutes in the real biomass liquors. When several electrolytes are present in a feed solution, electrical potential created across the membrane can lead to a significant Donnan effect and consequently alter the observed retention of the solute as compared to the single electrolyte system [30]. In the case of formic acid (46 Da, $\mathrm{pK}_{\mathrm{a}}=3.75$ [31]) in the WS liquor, Donnan effect was concluded to be the predominant mechanism due to the negative retentions obtained. Even though formic acid was supposed to be deprotonated above $\mathrm{pH}$ 
3.7 and the membrane negatively charged above $\mathrm{pH}$ 5, electrostatic repulsion of formic acid could apparently not counteract the Donnan effect significantly in the polyelectrolyte system. At $\mathrm{pH} 4.8$, acetic acid $\left(60 \mathrm{Da}, \mathrm{pK}_{\mathrm{a}}=4.75\right.$ [31] $)$ was less dissociated, which resulted in a retention close to zero for acetic acid in the WS and CS liquors, respectively (Figure 1).
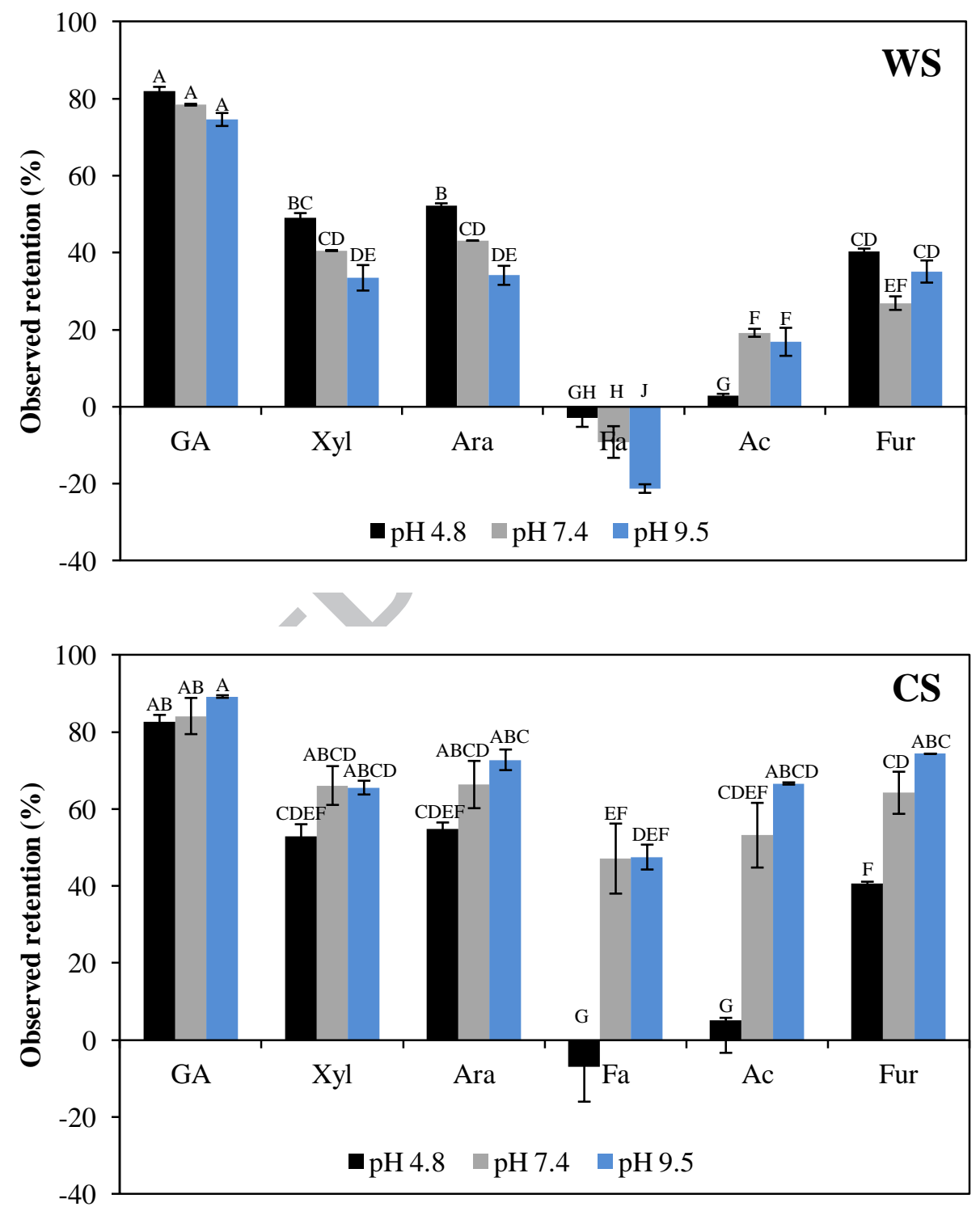


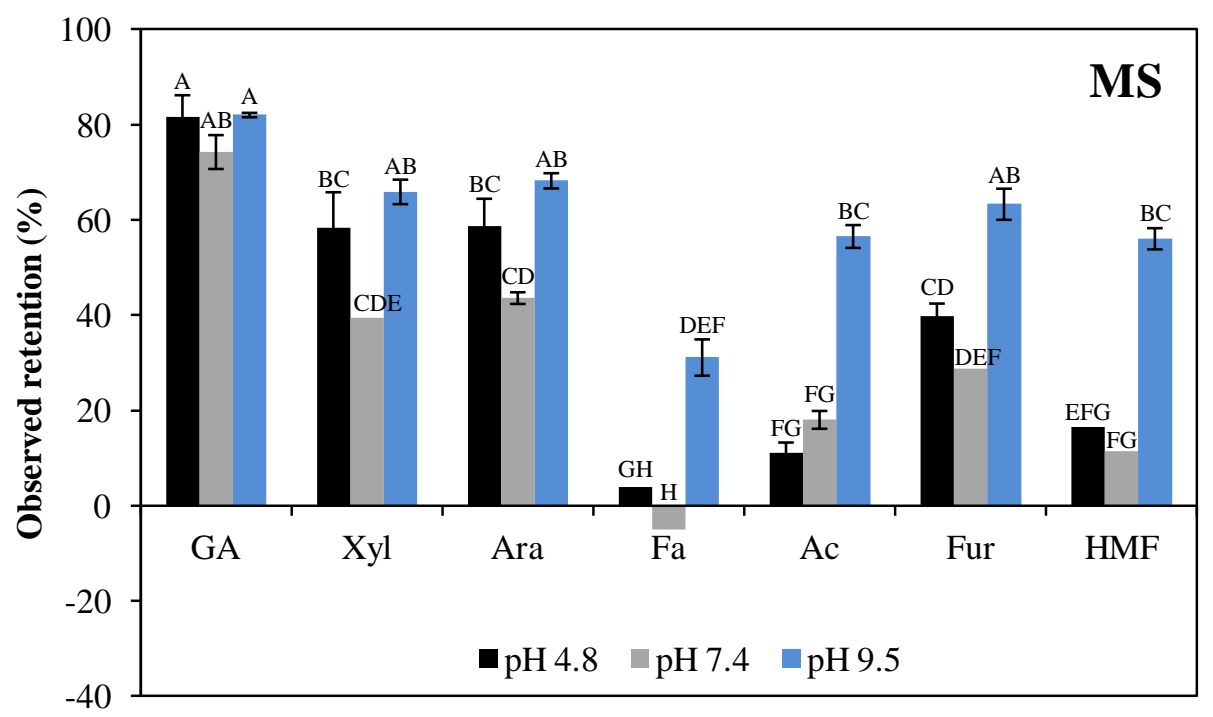

Figure 1. Observed retention (\%) of gluconic acid (GA), xylose (Xyl), arabinose (Ara), formic acid (FA), acetic acid (Ac), furfural (Fur) and HMF for wheat straw (WS), corn stover (CS) and Miscanthus stalks (MS). HMF retention is only shown for MS due to neglectable HMF concentrations in the WS and CS feedstocks. Similarly, retentions of phenols are not shown due to neglectable phenol concentrations in all the biomass liquors. Filtration was performed at $\mathrm{pH} 4.8, \mathrm{pH}$ 7.4 and $\mathrm{pH}$ 9.5, respectively, using the NF270 membrane at 4 bar and $250 \mathrm{rpm}$. Different superscript letters indicate statistically significant differences $(p<0.05)$ of averages obtained.

However, when $\mathrm{pH}$ was increased, the acetic acid became increasingly deprotonated, which caused the formic acid retention in the WS liquor to decrease, whereas the acetic acid retention increased probably as a result of the stronger Donnan effect at high $\mathrm{pH}$. Above $\mathrm{pH} 4.8$, electrostatic repulsion may also have contributed to the increase in acetic acid retention observed for all biomasses (Figure 1). However, if electrostatic repulsion was the predominant separation mechanism, it was anticipated that a higher retention would have been obtained at $\mathrm{pH} 9.5$. Indeed, for a system only containing xylose and acetic acid, Weng et al. [11] were able to reach acetic acid retentions above $90 \%$ at pH 9.1 using the Desal-5 DK membrane (MWCO: 150-300 Da). Similar results were obtained by Zhou et al. [10] for a system only containing xylose, glucose and acetic acid. Among the three acids detected in the biomass liquors, gluconic acid was assumed to be the least permeable, since it has higher molecular weight compared to formic acid and acetic acid, respectively. Since the Donnan effect was anticipated to be most prominent for the smaller ions, the 
decrease in gluconic acid retention from the model (98\%) to the real solution (80\%) was unexpected. The decrease in gluconic acid retention led to the suggestion that other charged solutes were also present in the real solutions. As an example, the presence of charged domains in the proteins/peptides detected in the biomass solutions could have decreased the retention of gluconic acid as a result of the Donnan effect. Furthermore, formation of other complex molecules resulting from interactions (similar to Maillard reactions) between the proteins/peptides, sugars and sugar degradation products [32] could also have affected the Donnan equilibrium. It was observed that the three biomass liquors became darker, when $\mathrm{pH}$ was increased, which indeed is a typical characteristic of sugar degradation and Maillard reactions [33]. It was also speculated whether such color change could result from interactions involving soluble low MW lignin residues [34]; however since low amounts of phenolic compounds were detected in the biomasses (Table 1), phenolic interactions probably were not the predominant cause of the color change. The lacking $\mathrm{pH}$ effect on the gluconic acid retention above the isoelectric point of the membrane could support the hypothesis that a significant Donnan effect was imposed on gluconic acid by the presence of larger electrolytes. On the other hand, the $\mathrm{pH}$ effect may simply have been counteracted by the increasing ionic strength of the solution leading to a less negative zeta potential of the NF membrane $[15,35,36]$. In that case, electrostatic repulsion would still have been the predominant separation mechanism leading to a lower retention of gluconic acid. While the gluconic acid retention was the same for each of the three biomasses, variations were observed with respect to the formic acid and acetic acid retentions, which may again have been explained by the nature of the feed solutions. If different components at different concentrations were present in the biomass liquors, the competition between electrostatic repulsion and the Donnan effect would also have been different for each of the feedstocks. For instance, electrostatic repulsion seemed more important in CS, since relatively higher formic and acetic acid retentions were obtained in CS as compared to the other two 
biomasses. On the other hand, the influence of the Donnan effect was generally more prominent in the WS and MS liquors.

\subsubsection{Addition of acetic acid}

In order to investigate whether the reduction in gluconic acid retention observed for the biomass liquors could be explained by the Donnan effect (caused by the presence of larger electrolytes) or weakened electrostatic repulsion (caused by the higher ionic strength), the permeate samples from the membrane bioreactor were spiked with acetic acid and further subjected to nanofiltration. Since $\mathrm{pH}$ alone was not concluded to have significant impact on the solute retention (cf. Figure 1), it was anticipated that the influence of ionic strength could be adequately studied through addition of acetic acid despite the simultaneous change in $\mathrm{pH}$. If the decrease was due to a Donnan effect, the addition of acetic acid was expected to increase the gluconic acid retention, whereas if the decrease was due to a higher ionic strength, the addition of acetic acid was expected to decrease the gluconic acid retention. However, the addition of acetic acid - which caused the solution $\mathrm{pH}$ to drop from 4.8 to 4.1 - did not influence the retention of either charged or non-charged solutes (Figure 2a) as compared to the original feed solutions at $\mathrm{pH} 4.8$ (Figure 1). According to the equilibrium law, the percent dissociation of formic acid, acetic acid, and gluconic acid at $\mathrm{pH} 4.1$ is $69 \%, 18 \%$ and $72 \%$, respectively. In comparison, the percent dissociation of formic acid, acetic acid and gluconic acid at pH 4.8 is $92 \%, 53 \%$ and $93 \%$, respectively. However, as the feed concentration of acetic acid in the experiments at $\mathrm{pH} 4.1$ was around four times higher than at $\mathrm{pH} 4.8$, the concentration of dissociated acid was practically the same at the two different $\mathrm{pH}$ values. Consequently, the Donnan equilibrium and the ionic strength were not significantly affected by the addition of acetic acid to the feed solutions, and so the retention of acids (particularly gluconic acid) was not significantly different from $\mathrm{pH} 4.1$ to 4.8 . In order to increase the concentration of dissociated acid in solution, the $\mathrm{pH}$ of the samples from the membrane bioreactor were first adjusted to $\mathrm{pH} 9.5$ before adding acetic acid to 
a concentration of $100 \mathrm{mM}$. Since the addition of acetic acid again reduced the $\mathrm{pH}$ to 4.6 , the $\mathrm{pH}$ was further readjusted with sodium hydroxide to 8.9 for MS (corresponding to a total concentration of $113 \mathrm{mM} \mathrm{NaOH}$ ) and to 9.7 for WS (corresponding to a total concentration of $122 \mathrm{mM} \mathrm{NaOH}$ ). The $\mathrm{pH}$ adjustment with sodium hydroxide now significantly altered the retention of charged as well as non-charged solutes (Figure $2 \mathrm{~b}$ ). Since the retention of gluconic acid was found to decrease with the increasing ionic strength (i.e. $\mathrm{pH}$ ), the hypothesis that the retention was governed by electrostatic repulsion rather than the Donnan effect was confirmed. Moreover, the increase in ionic strength at high $\mathrm{pH}$ also caused the retentions of the non-charged solutes (i.e. xylose, arabinose and furfural) to decrease. The decrease in non-charged solute retention may have been explained by the increasing adsorption of counter-ions inside the membrane pores. The increase in counter-ion concentration could have enhanced the electrostatic repulsion within the pores, which in turn may have increased the effective pore size thus resulting in a lower retention of non-charged solutes [37]. Even if the Donnan equilibrium was affected by the high concentration of sodium hydroxide in the system, the addition of sodium hydroxide still was not able to increase the retentions of the most permeable acids. The retentions of formic acid and acetic acid may thus also have been suppressed by the less negative zeta potential of the nanofiltration membrane; especially when taking into account that the molecular weights of the acids were considerably lower than the membrane cut-off. However, the negative retentions (particularly observed for formic acid) still indicated that Donnan effect was important too.

\subsubsection{Overall comparison of the model solution and biomass liquors}

A general evaluation of the downstream separation performance led to the conclusion that the purification of xylose was significantly influenced by the complexity of the biomass liquors; especially the high ionic strength which led to a less negative zeta potential and thus decreased the electrostatic repulsion between gluconic acid and the surface of the membrane as compared to the 
model solution. Consequently, the resulting purity of xylose with respect to gluconic acid was $91 \%$ (vs. $>99 \%$ for the model solution), whereas the purity of xylose with respect to all components was only $60 \%$. In both cases, the yield of xylose was $30 \%$ (vs. $41 \%$ for the model solution).

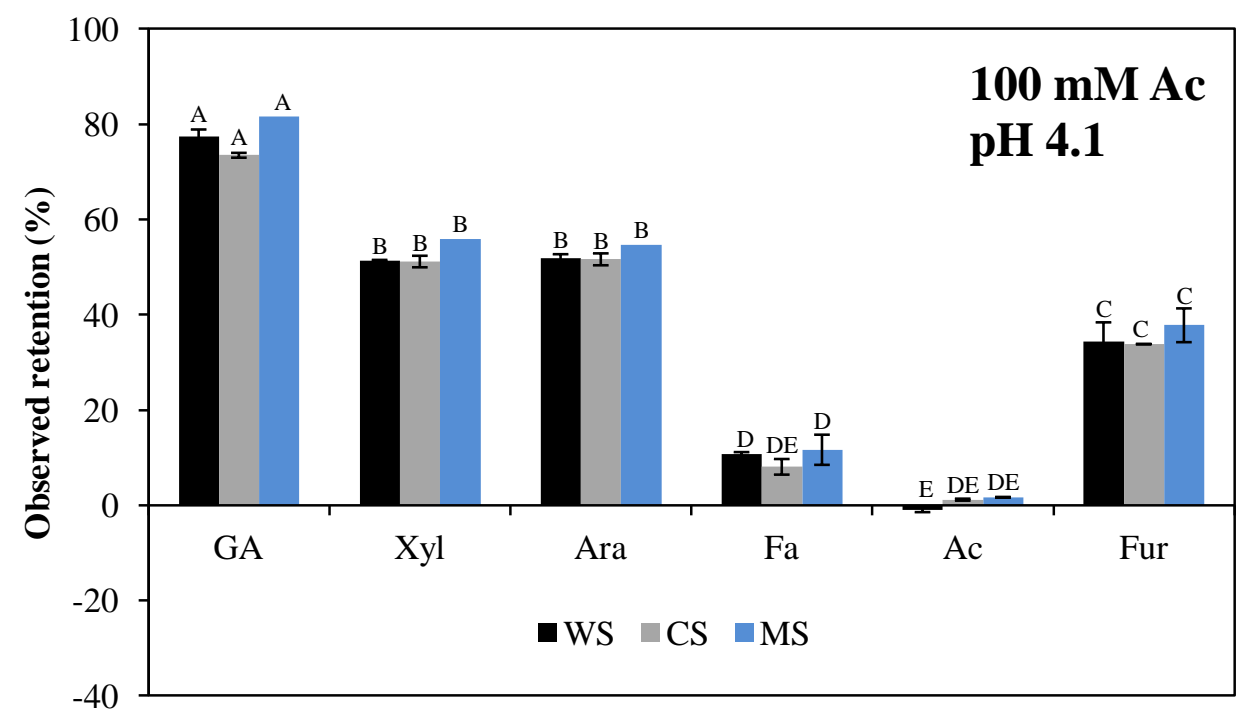

(a)

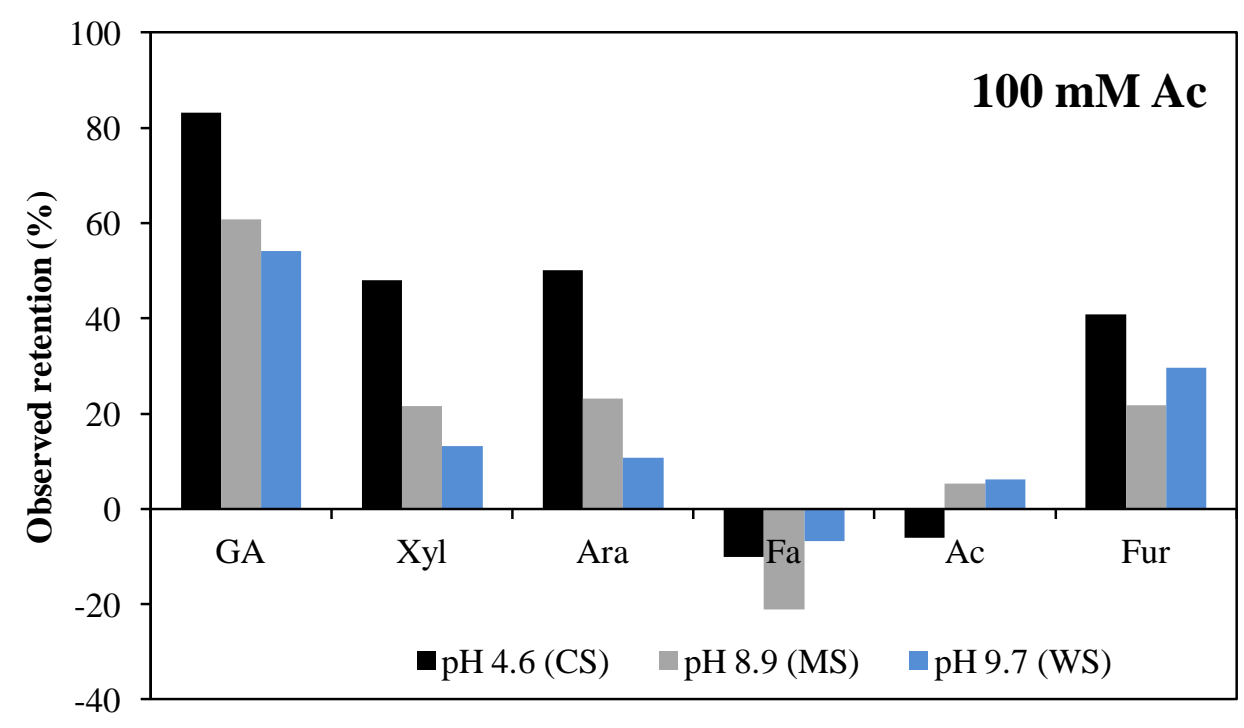

(b)

Figure 2. Observed retention (\%) of gluconic acid (GA), xylose (Xyl), arabinose (Ara), formic acid (FA), acetic acid (Ac) and furfural (Fur) for wheat straw (WS), corn stover (CS) and Miscanthus stalks (MS). Retentions of phenols and HMF are not shown due to neglectable concentrations of HMF in the WS and CS liquors. Feed solutions were spiked with acetic acid to a total concentration of $100 \mathrm{mM}$. Filtration was performed with the NF270 membrane at 4 bar and $250 \mathrm{rpm}$. a) $\mathrm{pH}=4.1$ for all biomass samples (no addition of $\mathrm{NaOH}$ ); b) $\mathrm{pH}=9.7$ for WS (corresponding to $122 \mathrm{mM}$ $\mathrm{NaOH}$ ), $\mathrm{pH}=4.6$ for $\mathrm{CS}$ (corresponding to $33 \mathrm{mM} \mathrm{NaOH}$ ), $\mathrm{pH}=8.9$ for $\mathrm{MS}$ (corresponding to 113 $\mathrm{mM} \mathrm{NaOH})$. 
However, despite the lower performance of the enzyme-assisted membrane system on the real biomass liquors, the separation of xylose from gluconic acid was still improved compared to the benchmark separation of xylose from glucose. In fact, the separation factor of gluconic acid over xylose was 2.7, 2.5 and 2.2 for WS, CS and MS, respectively, whereas the xylose separation factor with respect to glucose was only 1.4 [3]. Generally, the WP loss obtained for the biomass liquors ( 14\% irrespective of biomass) was comparable with the WP loss obtained for the model solution, which indicated that despite the increasing complexity of the real biomass feedstocks, fouling was not a big limitation in the real system either. Similar conclusions were obtained by Weng et al. [38] when subjecting dilute acid rice straw hydrolysates to NF. The permeate flux obtained for the WS, CS and MS liquors was generally higher above the isoelectric point of the membrane (Figure 3), which was likely explained by the improved wettability of the membrane at high $\mathrm{pH}$ [39]. However, the flux achieved at $\mathrm{pH} 9.5$ for the biomass liquors was still significantly lower than the flux obtained at $\mathrm{pH} 9.5$ for the model solution $\left(18.7 \mathrm{Lm}^{-2} \mathrm{~h}^{-1}\right.$ at 4 bar [3]), which was ascribed to the higher viscosity and osmotic pressure of the real liquors [40].

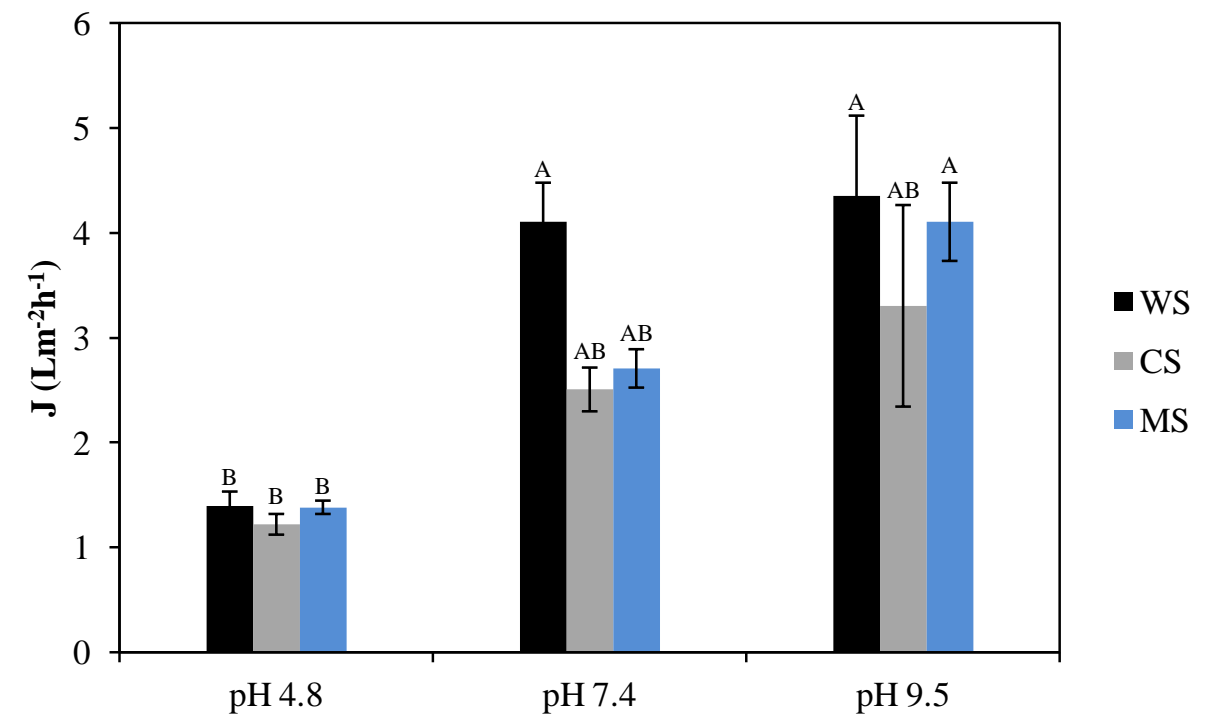

Figure 3. Average permeate flux for $4 \mathrm{~mL}$ permeate of wheat straw (WS), corn stover (CS) and Miscanthus stalks (MS). Filtration was performed at $\mathrm{pH} 4.8, \mathrm{pH} 7.4$ and $\mathrm{pH} 9.5$, respectively, using the NF270 membrane at 4 bar and $250 \mathrm{rpm}$. Different superscript letters indicate statistically significant differences $(\mathrm{p}<0.05)$ of averages obtained 


\section{Conclusions}

The aim of the present study was to assess the performance of an enzyme-assisted membrane system (developed for pure model solutions of xylose and glucose) on genuine biorefinery liquors obtained from hydrothermal pretreatment of wheat straw, corn stover and Miscanthus stalks. Despite the solute complexity of the real biomass liquors, fouling in the membrane (UF) bioreactor was neglectable and the biocatalytic productivity of the coupled enzyme system (glucose oxidase/catalase) was comparable to the model solution (24 mg gluconic acid/mg enzyme). On the other hand, the downstream purification of xylose was hampered by the elevated number of compounds in the biomass liquors, resulting in a higher ionic strength of the feed solution, which had direct impact on the zeta potential and hence the overall separation performance. Further downstream separation would depend on the desired purity and recovery of xylose. Moreover, a techno-economic analysis (which has not been done in this study) could probably reveal whether the price of xylose and other value-added products obtained by enzyme-assisted NF could adequately justify the implementation of new process steps, utilities, enzymes and chemicals presented in this work.

\section{Acknowledgements}

This work was supported by the Bio-Value Strategic Platform for Innovation and Research, cofunded by The Danish Council for Strategic Research and The Danish Council for Technology and Innovation, case no: 0603-00522B.

\section{References}

[1] P. Gallezot, Conversion of biomass to selected chemical products, Chem. Soc. Rev. 41 (2012 1538-1558. 
[2] V. Menon, M. Rao, Trends in bioconversion of lignocellulose: Biofuels, platform chemicals \& biorefinery concept, Prog. Energy Combust. Sci. 38 (2012) 522-550.

[3] S.T. Morthensen, J. Luo, A.S. Meyer, H. Jørgensen, M. Pinelo, High performance separation of xylose and glucose by enzyme assisted nanofiltration, J. Memb. Sci. 492 (2015) 107-115.

[4] S. Ramachandran, Gluconic acid: Properties, applications and microbial production, Food Technol. Biotechnol. 44 (2006) 185-195.

[5] S. Ferri, K. Kojima, K. Sode, Review of glucose oxidases and glucose dehydrogenases: A bird's eye view of glucose sensing enzymes. J. Diabetes Sci. Technol. 5(5) (2011) 1068-1076.

[6] S.T. Morthensen, A.S. Meyer, H. Jørgensen, M. Pinelo, Significance of membrane bioreactor design on the biocatalytic performance of glucose oxidase and catalase: Free vs. immobilized enzyme systems, Biochem. Eng. J. 117 (2017) 41-47.

[7] S.T. Morthensen, S.B. Sigurdardóttir, A.S. Meyer, H. Jørgensen, M. Pinelo, Separation of xylose and glucose using an integrated membrane system for enzymatic cofactor regeneration and downstream purification, J. Membr. Sci. 523 (2017) 327-335.

[8] H. Rasmussen, D. Tanner, H.R. Sørensen, A.S. Meyer, New degradation compounds from lignocellulosic biomass pretreatment: routes for formation of potent oligophenolic enzyme inhibitors, Green Chem. 19 (2016) 464-473.

[9] Y. He, D.M. Bagley, K.T. Leung, S.N. Liss, B.Q. Liao, Recent advances in membrane technologies for biorefining and bioenergy production, Biotechnol. Adv. 30 (2012) 817-858.

[10] F. Zhou, C. Wang, J. Wei, Separation of acetic acid from monosaccharides by NF and RO membranes: Performance comparison, J. Membr. Sci. 429 (2013) 243-251. 
[11] Y.H. Weng, H.J. Wei, T.Y. Tsai, W.H. Chen, T.Y. Wei, W.S. Hwang, C.P. Wang, C.P. Huang, Separation of acetic acid from xylose by nanofiltration, Sep. Purif. Technol. 67 (2009) 95-102.

[12] J. Luo, B. Zeuner, S.T. Morthensen, A.S. Meyer, M. Pinelo, Separation of phenolic acids from monosaccharides by low-pressure nanofiltration integrated with laccase pre-treatments, J. Memb. Sci. 482 (2015) 83-91.

[13] B. Qi, J. Luo, X. Chen, X. Hang, Y. Wan, Separation of furfural from monosaccharides by nanofiltration, Bioresour. Technol. 102 (2011) 7111-7118.

[14] J. Luo, Y. Wan, Effects of $\mathrm{pH}$ and salt on nanofiltration - a critical review, J. Membr. Sci. 438 (2013) 18-28.

[15] M.R. Teixeira, M.J. Rosa, M. Nyström, The role of membrane charge on nanofiltration performance, J. Membr. Sci. 265 (2005) 160-166.

[16] D.T. Djajadi, A.R. Hansen, A. Jensen, L.G. Thygesen, M. Pinelo, A.S. Meyer, H. Jørgensen, Surface properties correlate to the digestibility of hydrothermally pretreated lignocellulosic Poaceae biomass feedstocks, Biotechnol Biofuels 10:49 (2017).

[17] J. Agger, A.V. Nielsen, A.S. Meyer, Enzymatic xylose release from pretreated corn bran arabinoxylan: Differential effects of deacetylation and deferuloylation on insoluble and soluble substrate fractions, J. Agric. Food Chem. 58 (2010) 6141-6148.

[18] T.S. Fernandes, L.C. Duarte, F. Carvalheiro, M.C.L. Dias, C. Fonseca, F. Gírio, Hydrothermal pretreatment of several lignocellulosic mixtures containing wheat straw and two hardwood residues available in Southern Europe, Bioresour. Technol. 183 (2015) 213-220. 
[19] R.J. Patinvoh, A.K. Mehrjerdi, I.S. Horváth, M.J. Taherzadeh, Dry fermentation of manure with straw in continuous plug flow reactor: Reactor development and process stability at different loading rates, Bioresour. Technol. 224 (2017) 197-205.

[20] J. Holck, A. Lorentzen, L.K. Vigsnæs, T.R. Licht, J.D. Mikkelsen, A.S. Meyer, Feruloylated and nonferuloylated arabino-oligosaccharides from sugar beet pectin selectively stimulate the growth of bifidobacterium spp. in human fecal in vitro fermentations, J. Agric. Food Chem. 59 (2011) 6511-6519.

[21] Z. Wang, Z. Wu, X. Yin, L. Tian, Membrane fouling in a submerged membrane bioreactor (MBR) under sub-critical flux operation: Membrane foulant and gel layer characterization, J. Membr. Sci. 325 (2008) 238-244.

[22] U. Metzger, P.L. Clech, R.M. Stuetz, F.H. Frimmel, V. Chen, Characterization of polymeric fouling in membrane bioreactors and the effect of different filtration modes, J. Membr. Sci. 301 (2007) 180-189.

[23] M.Y. Jaffrin, Dynamic shear-enhanced membrane filtration: A review of rotating disks, rotating membranes and vibrating systems, J. Membr. Sci. 324 (2008) 7-25.

[24] G.M. Rios, M.P. Belleville, D. Paolucci, J. Sanchez, Progress in enzymatic membrane reactors - a review, J. Membr. Sci. 242 (2004) 189-196.

[25] A.K.R. Landbo, M. Pinelo, A.F. Vikbjerg, M.B. Let, A.S. Meyer, Protease-assisted clarification of black currant juice: Synergy with other clarifying agents and effects on the phenol content, J. Agric. Food Chem. 54 (2006) 6554-6563.

[26] K.J. Siebert, Haze formation in beverages. LWT 39 (2006) 987-994. 
[27] M.S.M. Sueb, J. Zdarta, T. Jesionowski, G. Jonsson, A.S. Meyer, H. Jørgensen, M. Pinelo, High-performance removal of acids and furans from wheat straw pretreatment liquid by diananofiltration, Sep. Sci. Technol. http://dx.doi.org/10.1080/01496395.2017.1302951.

[28] S.K. Maiti, Y.L. Thuyavan, S. Singh, H.S. Oberoi, G.P. Agarwal, Modelling of the separation of inhibitory components from pretreated rice straw hydrolysate by nanofiltration membranes, Bioresour. Technol. 114 (2012) 419-427.

[29] F. Liu, S. Sivoththaman, Z. Tan, Solvent extraction of 5-HMF from simulated hydrothermal conversion product, Sustain. Environ. Res. 24(2) (2014) 149-157.

[30] H.M. Krieg, S.J. Modise, K. Keizer, H.W.J.P. Neomagus, Salt rejection in nanofiltration for single and binary salt mixtures in view of sulphate removal, Desalination 171 (2004) 205-215.

[31] S.S. Zumdahl, Appendix 5 in Chemical Principles, sixth ed., Houghton Mifflin, Boston, 2007.

[32] A.A. Peterson, R.P. Lachance, J.W. Tester, Kinetic evidence of the maillard reaction in hydrothermal biomass processing: Glucose-glycine interactions in high-temperature, high-pressure water, Ind. Eng. Chem. Res. 49 (2010) 2107-2117.

[33] E.H. Ajandouz, A. Puigserver, Nonenzymatic browning reaction of essential amino acids: Effect of $\mathrm{pH}$ on caramelization and Maillard reaction kinetics. J. Agric. Food Chem. 47 (1999) 1786-1793.

[34] J. Pérez, J.M. Dorado, T.D.L. Rubia, J. Martínez, Biodegradation and biological treatments of cellulose, hemicellulose and lignin: an overview, Int. Microbiol. 5 (2002) 53-63.

[35] E.M. Vrijenhoek, S. Hong, M. Elimelech, Influence of membrane surface properties on initial rate of colloidal fouling of reverse osmosis and nanofiltration membranes, J. Membr. Sci. 188 (2001) 115-128. 
[36] J.M.M. Peeters, M.H.V. Mulder, H. Strathmann, Streaming potential measurements as a characterization method for nanofiltration membranes, Colloids Surf., A 150 (1999) 247-259.

[37] A. Escoda, P. Fievet, S. Lakard, A. Szymczyk, S. Déon, Influence of salts on the rejection of polyethyleneglycol by an NF organic membrane: Pore swelling and salting-out effects, J. Membr. Sci. 347 (2010) 174-182.

[38] Y.H. Weng, H.J. Wei, T.Y. Tsai, T.H. Lin, T.Y. Wei, G.L. Guo, C.P. Huang, Separation of furans and carboxylic acids from sugars in dilute acid rice straw hydrolyzates by nanofiltration, Bioresour. Technol. 101 (2010) 4889-4894.

[39] J. Yang, S. Lee, E. Lee, J. Lee, S. Hong, Effect of solution chemistry on the surface property of reverse osmosis membranes under seawater conditions, Desalination 247 (2009) 148-161.

[40] A.K. Gautam, T.J. Menkhaus, Performance evaluation and fouling analysis for reverse osmosis and nanofiltration membranes during processing of lignocellulosic biomass hydrolysate, J. Membr. Sci. 451 (2014) 252-265. 


\section{Highlights}

- Enzyme-assisted NF for separation of xylose from biomass liquors is performed

- Maximum biocatalytic productivity can be obtained in the membrane bioreactor

- Gel layer fouling can be avoided by acid hydrolysis of the biomass liquors

- Xylose purification by NF is governed by the ionic strength of the biomass liquors 